\title{
Feed restriction and insulin-like growth factor-I (IGF-I) affect the oocyte maturation in matrinxã Brycon amazonicus
}

\author{
Luís Henrique Montrezor ${ }^{1,2}$ and Elisabeth Criscuolo Urbinati ${ }^{3}$ \\ Department of Biological Science and Health, UNIARA, Araraquara, São Paulo, Brazil; Medical Chemistry and Regenerative \\ Medicine Group, QUIMMERA, UNIARA, Araraquara, São Paulo, Brazil; and Department of Animal Morphology and \\ Physiology/Aquaculture Center, UNESP, Jaboticabal, São Paulo, Brazil
}

Date submitted: 07.05.2016. Date revised: 10.09.2016. Date accepted: 06.10.2016

\section{Summary}

The feeding and nutrition of breeders are crucial aspects in the reproductive process. During the maturation period, metabolic changes occur aiming at mobilizing energy for growth and follicular development. The involvement of IGF-1 in metabolic and reproductive events is important. The aim of this work was to evaluate if alternate feed restriction and re-feeding have permissive effects on in vitro actions of IGF-1 on oocytes development of matrinxã. In vivo experiments were performed during vitellogenesis period. Females $(n=60)$ were fed with a commercial feed ( $2 \%$ of biomass) and they were divided into two treatments: fish receiving food daily (control - fed), and fish submitted to cycles of 3 days of feed restriction and 2 days of re-feeding (no-fed group). For the in vitro experiments, oocytes $(n=20)$ were obtained from the ovaries removed at the end of the in vivo experiment and were divided into four groups: fed -IGF-1; fed +IGF-1; no-fed -IGF-1 and no-fed +IGF-1. Fish under restriction had lower body weights, decreased plasma glucose, increased triglycerides levels, and their final maturation and mature oocyte were reduced and the atresic ones were in higher number. Moreover, IGF-1, in vitro, increased the percentage of mature oocytes in fed females and decreased the atresic ones. In no-fed females, IGF-1 increased the final maturation and mature oocytes and reduced the atresic ones. This study demonstrates the importance of the feeding management of female breeders of matrinxã during the vitellogenesis period.

Keywords: Fish, Food restriction, IGF-1, Matrinxã, Oocyte development

\section{Introduction}

Worldwide, the fish production from capture fisheries has levelled off and most of the main fishing areas have reached their maximum output potential (Naylor et al., 2000). Aquaculture is important for the sustainability of commercial fish supplies, and currently yields a

\footnotetext{
${ }^{1}$ All correspondence to: Luís Henrique Montrezor. University of Araraquara, UNIARA, Department of Biological Science and Health - Medicine, Rua Voluntários da Pátria, 1309, 140801-320 - Araraquara - SP, Brazil. Tel: +55 16 33017300 - 7351. E-mail: lhmontrezor@uniara.com.br ${ }^{2}$ Medical Chemistry and Regenerative Medicine Group, QUIMMERA, UNIARA, Araraquara, São Paulo, Brazil.

${ }^{3}$ Department of Animal Morphology and Physiology/ Aquaculture Center (CAUNESP), University of Estadual Paulista, UNESP, Jaboticabal, São Paulo, Brazil.
}

total production of more than 150 million tons per year (FAO, 2012).

Studies on teleost fish reproduction may assist the aquaculture industry in meeting the ever increasing demand for fish, by improving protocols for higher efficiency of egg production and enhanced viability of progeny. One of the main concerns of the aquaculture industry is the production of large number of viable eggs. Until recently, most of research efforts were focused in the endocrine regulation of spawning and optimizing rearing protocols (Lubzen et al., 2010).

Numerous circulating endocrine and locally acting paracrine and autocrine factors regulate the oocyte developmental and maturation stages. Although it is clear that the major regulators during vitellogenesis and oocyte maturation are the pituitary gonadotropins (luteinizing hormone, LH, and follicle-stimulating hormone, FSH) and sex steroids. The picture emerging 
from recent studies is of complex hormone crosstalk at all stages between the developing oocyte and its surrounding follicle layers to ensure coordination of the various processes that are involved in the production of a fertilizable egg (Lubzen et al., 2010).

Insulin-like growth factor-I (IGF-1), whether systemic or produced by follicle granulosa cells (GC) (Kagawa et al., 1995; Schmid et al., 1999; Perrot et al., 2000; Berishivili et al., 2006), has been implicated in the regulation of the ovarian steroidogenesis, although the underlying mechanisms are still unclear. IGF-1 inhibited steroid production by thecal layers in Coho salmon ovarian follicles, yet stimulated steroid production by granulosa layers (Maestro et al., 1997b). Furthermore, IGF-1 increased cytochrome P450 side-chain cleavage (CYP 11A1A) expression in red sea bream (Kagawa et al., 2003) and trout ovarian follicles (Nakamura et al., 2003). IGF-1 receptors are expressed in both layers of carpa follicles (Maestro et al., 1997a) and the expression of both IGF-1 and IGF-1 receptors in the ovaries of sterlet (Ancipenser ruthenus) became elevated at the onset of vitellogenesis (Wuertz et al., 2007a). Together, these studies indicated that the IGF-1 signalling system is important in regulating steroidogenic activity of the ovarian follicles during vitellogenesis. In addition to affecting the steroidogenic machinery, mitogenic effects of IGF-1 on GC at the onset of vitellogenesis have been suggested (Kagawa et al., 1995).

Physiological mechanisms through which nutrient intake controls reproductive events in fish are complex and not fully understood. Secretion of hormones from endocrine organs such as the gastric and intestinal mucosa or the pancreas is directly activated by ingested nutrients (McIntosh, 1995; MacKenzie et al., 1998), whereas ingested carbohydrates or amino acids have been suggested to play a role in the regulation of pituitary and thyroid hormone production (Danforth \& Burger, 1989; Ghigo et al., 1992; MacKenzie et al., 1998; Celik et al., 2015).

Food deprivation is the most common tool for the examination of endocrine-nutrient interactions. As periods of fasting are often a natural part of the life cycle of fish, many species are highly tolerant of prolonged food deprivation (MacKenzie et al., 1998). This tolerance provides a tool to examine the dynamics of endocrine response to the cessation of nutrient intake as well as the reproductive responses. Fish on restricted rations reduce energy storage, growth and reproduction, redirecting energy towards the maintenance of metabolism. This change is reflected in a suite of physiological response to food restriction: decreased growth rate, condition factor, organ weight (liver, muscle, and adipose tissue), and an increase in the mobilization of glucose, lipid and amino acids from storage (Navarro \& Gutiérrez, 1995; MacKenzie et al.,
1998). However, the mechanisms underlying dietary restriction are not yet understood.

In previous studies, matrinxã (Brycon amazonicus), an economically important freshwater fish on South America, undergoing controlled feed restriction (3 days fed and 2 days no-fed) did not show any reduction of growth and preserved gonadal maturation (Urbinati et al., 2004). Moreover, Camargo \& Urbinati (2008) did not find any difference between females and offspring performance of fish fed continuously or under food reduction. The ability demonstrated by matrinxã to overcome the reduction in nutrient intake, maintaining body weight, gonadal development and quality of gametes and offspring suggests the existence of hormonal mechanisms and energy use activated by food restriction that can be developed in this species.

Thus, an examination of the role of nutrients in regulating endocrine activity in fish may provide us with both practical information on the physiological consequences of the manipulation of feeding as well as comparative data contributing to our understanding of the physiology reproduction mechanisms. Therefore, the objective of this work was to study if alternate feed restriction and re-feeding has permissive effects on in vitro actions of IGF-1 on oocytes stages of matrinxã.

\section{Materials and methods}

\section{Fish and experimental protocol}

The study utilized 60 breeders of matrinxã supplied by the Aquaculture Center of UNESP, Jaboticabal campus, UNESP, and was made up by two phases: an in vivo trial and an in vitro assay.

This research followed the Ethical Principles in Animal Research adopted by the National Council for the Control of Animal Experimentation - Brazil (CONCEA).

\section{In vivo experiments}

These experiments were performed during the vitellogenesis period, from August to November. The broodstock was distributed in six earthen tanks $(n=10)$ in June, 1 month before the beginning of vitellogenesis for acclimation to the experimental conditions. The oxygen concentration and the water temperature in the ponds were monitored weekly. The mean oxygen concentration was $5.0 \mathrm{mg} / 1 \pm 0.4$ $\mathrm{mg} / \mathrm{l}$ and the mean water temperature $27.7 \pm 2.1^{\circ} \mathrm{C}$ along the experiment. During the experiment, fish were fed with a commercial feed at a ration of $2 \%$ of biomass. Two treatments were established: (a) fish receiving food daily/control/fed group (three tanks); (b) experimental fish submitted to cycles of 3 days of 
feed restriction and 2 days of re-feeding/no-fed group (three tanks), according to Camargo \& Urbinati (2008).

Fish from both treatments were sampled $(n=6)$ when they presented external characteristics of advanced gonadal maturation, such as swollen abdomen, reddish urogenital papilla and bulging coelomic cavity. Anesthetized fish (benzocaine $0.4 \mathrm{mg} / 10 \mathrm{ml}$ alcohol/15 1 water) were bled in the caudal veins with heparinized syringes to measure glucose and triglycerides levels. The blood glucose and triglycerides concentrations were measured by enzymatic methods (Labtest Kit, São Paulo, Brazil). Fish were then euthanized (benzocaine $1.0 \mathrm{~g} / 10 \mathrm{ml}$ alcohol/15 1 water), measured and weighed. Liver and ovaries were removed and weighed in order to calculate the gonadal and hepatosomatic indices [(organ weight/body weight) $\times$ 100].

\section{In vitro experiments}

The ovaries removed at the end of in vivo experiment were maintained in phosphate-buffered saline (PBS) and the oocytes were mechanically dissected. The collected oocytes were cultured in 24-well plates (20 oocytes/well/ml) in Leibowitz medium supplemented with $20 \mathrm{nM}$ HEPES, antibiotics $(1000 \mathrm{U} / \mathrm{ml}$ penicillin and $100 \mu \mathrm{g} / \mathrm{ml}$ streptomycin) and $0.1 \%$ bovine serum albumin (BSA), in a final volume of 1.0 ml, pH 7,5 (Pankhurst, 1997; Miwa et al., 2001; Kagawa et al., 2003). After weighing the ovaries, all procedures were performed in a laminar flow hood to prevent contamination of the cultures.

The oocytes were divided into four treatments: (1) fed -IGF-1; (2) fed +IGF-1 (0, 1, 10 or $50 \mathrm{nM}$ ) (Negatu et al., 1998); (3) no-fed -IGF-1; and (4) no-fed +IGF-1 (0, 1,10 or $50 \mathrm{nM}$ ). The assays were performed in triplicate and the plates were incubated at $26^{\circ} \mathrm{C}$ for $3,6,12,24$ or $48 \mathrm{~h}$. After, to determine the best time of culture (data not shown), the assay were carried out for 3-h culture.

All the media, buffers, supplements, reagents, insulin and IGF-1 for cell culture were obtained from Sigma-Aldrich Co (St. Louis, MO, USA).

\section{Microscopic analysis of oocytes}

For the morphological analysis, at the end of each culture time, the oocytes were removed from the plates and fixed in $4 \%$ formaldehyde buffer for $24 \mathrm{~h}$. Thereafter, the samples were dehydrated and embedded in paraffin. Samples were cut in $9-\mu \mathrm{m}$ serial sections, stained with haematoxylin and eosin (HE), and photographs were analyzed with Motic Live Imaging Module (format $1024 \times 768$ ) microscopy software. The oocytes were classified in different stages: final maturation, matured and atresic. The final maturation oocyte were determined by the smooth chorion, abundance of intact vitellus grain, nuclei irregularly presenting several perinucleolar nucleoli; the mature oocytes by nuclei migration to the periphery of the oocyte, usually toward the micropyle (which was observed in some slices), and the atresic oocytes by loose chorion, thin or thickened, several zigzag folds, invaginations into the oocyte, ruptures and fragmentations; vitellus with fragmentation and liquefaction of beads; GC hypertrophied (especially at $48 \mathrm{~h}$ of culture) and disorganized nuclei.

\section{Statistical analysis}

All data were performed using the general linear model (Proc GLM) of SAS software (Statistical Analysis System Institute Inc. Cary, NC, USA). From the statistical analysis using the different statistical models, we observed that the significant covariates affecting the compositions in each sample unit were given by: time $(3,6,12,24$ or $48 \mathrm{~h}$ ); group (control and treatment) and hormone IGF- $1(0,1,10$ or 50 $\mathrm{nM})$. Thus, the statistical model included time of culture, group of treatment, hormone concentration and interactions. For body weight, body length, gonadal somatic index, hepatosomatic index, blood glucose and blood triglycerides the data were analyzed using two-way analysis of variance (ANOVA) for repeated measures and Tukey's test was used for multiples comparisons. The values were expressed as means \pm standard error of the mean (SEM) and a $P$-value less than 0.05 was considered statistically significant.

\section{Results}

\section{In vivo experiment}

Body weight, body length, gonadal and hepatosomatic indices

The feeding regimes tested affected the body weight, gonadal development and hepatosomatic index. Females (from no-fed group) had lower body weight (Fig. 1A) and lower gonadal development (Fig. 1C) compared with females from the fed group $(P<0.05)$. The hepatosomatic index (Fig. 1D) of no-fed females was higher compared with females from the fed group $(P<0.05)$.

\section{Blood glucose and blood triglycerides}

The feeding regimes also affected the blood glucose and triglycerides levels. The blood glucose was lower in the no-fed group compared with the fed group (Fig. 2A), and the blood triglycerides were higher in no-fed group compared with the fed group (Fig. 2B) $(P<0.05)$. 

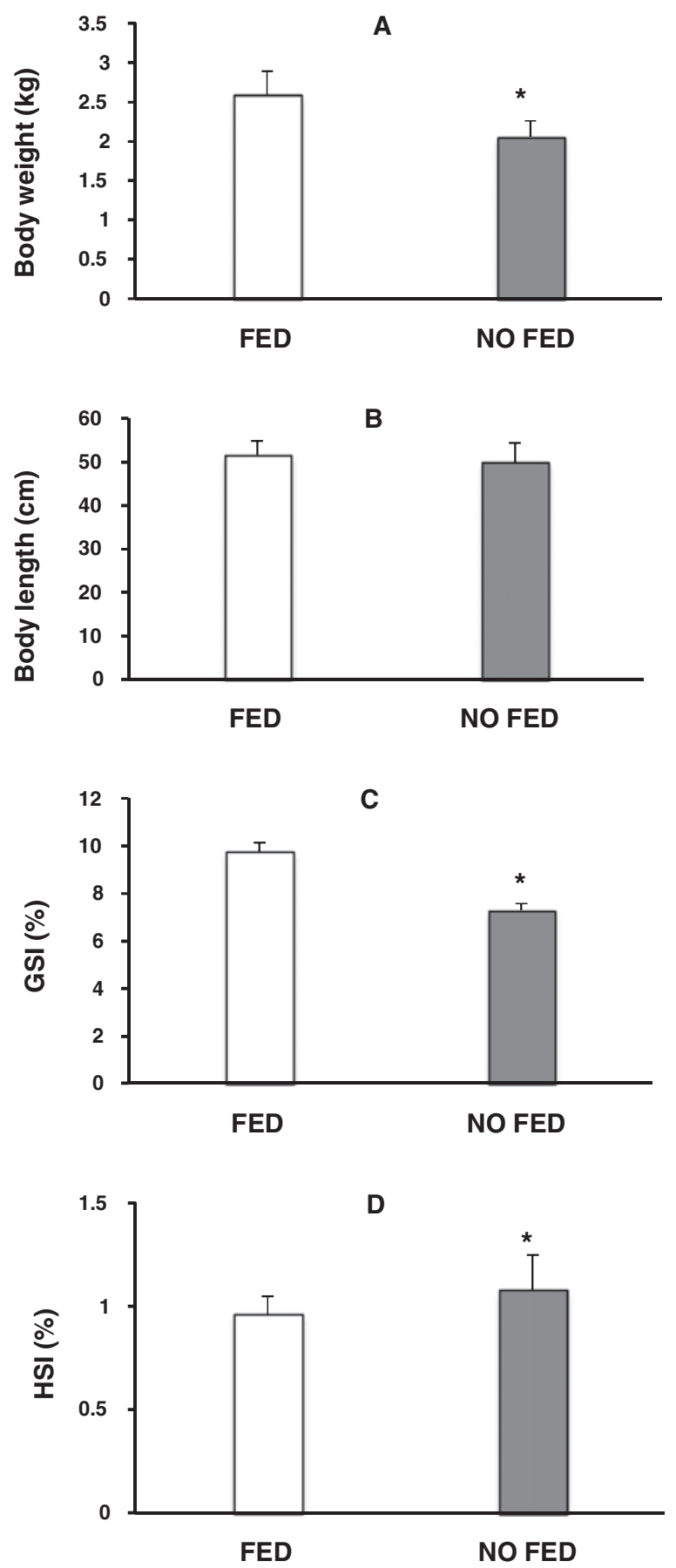

Figure 1 Effects of fed group versus no-fed group on matrinxã body weight $(A)$, body length $(B)$, gonadal somatic index $(C)$ and hepatosomatic index $(D)$. Results are represented as means \pm standard error of the mean (SEM). ${ }^{*} P<0.05$.

\section{In vitro assays}

Oocyte development stages between groups ( $f e d \times$ no-fed) and times $(0 \mathrm{~h}$ or $3 \mathrm{~h})$ of culture

Figure 3 shows the percentage of oocyte in the different stages of development before and after $3 \mathrm{~h}$ of culture. We observed that the percentage of oocytes in final
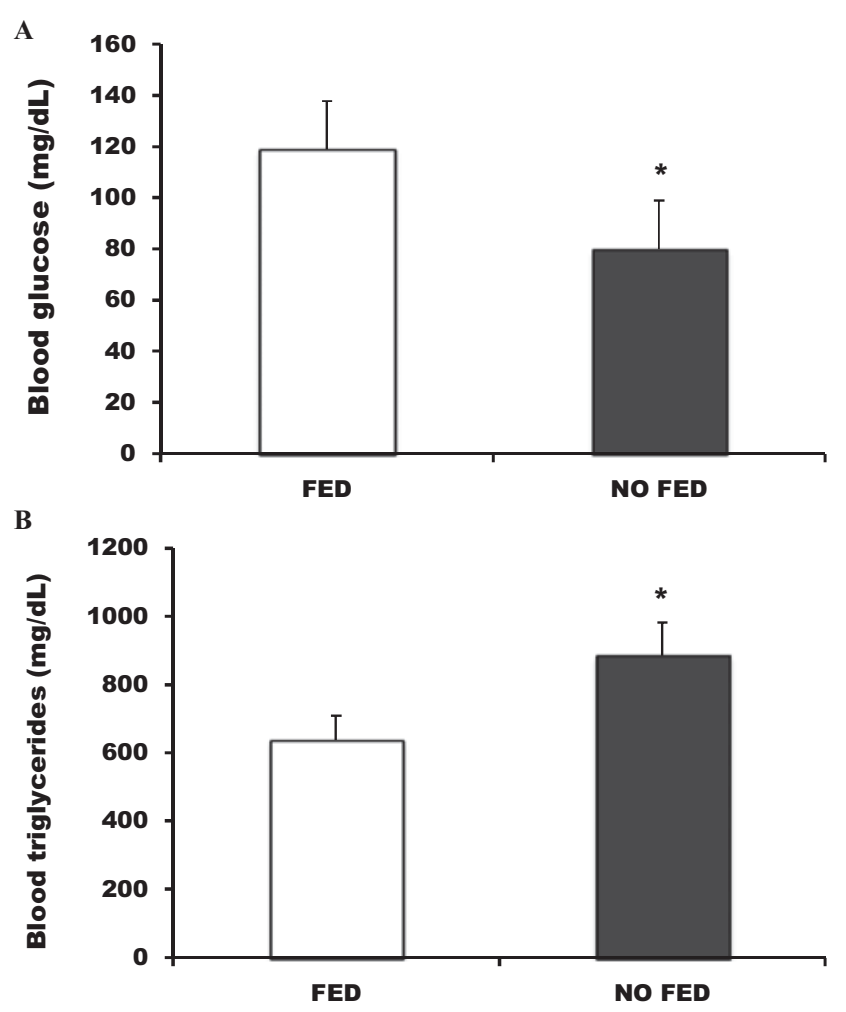

Figure 2 Effects of fed group versus no-fed group on matrinxã blood glucose $(A)$ and blood triglycerides $(B)$. Results are represented as means \pm standard error of the mean (SEM). ${ }^{*} P<0.05$.

maturation was higher in the fed group compared with the other two stages found (mature and atresic), independent of time. In addition, in the fed group, the percentage of mature oocytes was higher than in atresic oocytes $(P<0.05)$. Regarding the no-fed group, we observed that at $0 \mathrm{~h}$, the percentage of mature oocytes was lower than in final maturation and atresic stages. In the same group, at time $3 \mathrm{~h}$, the percentage of atresic oocytes was higher compared to the other two stages and the percentage of final maturation oocytes was higher compared to the mature oocytes $(P<0.05)$. Comparing the groups, we observed that the percentage of final maturation oocytes was higher in the fed group compared with the no-fed group at $0 \mathrm{~h}$ and $3 \mathrm{~h}$. Similarly, the percentage of mature oocytes was higher in the fed group at $0 \mathrm{~h}$ and $3 \mathrm{~h}$, compared with the no-fed group at the same times. The percentage of atresic oocytes was higher at $3 \mathrm{~h}$ in the no-fed group compared with $0 \mathrm{~h}$, in the same group and it was higher than the percentage of oocytes at the same stage in the fed group at both times. Finally, the percentage of atresic oocytes at $0 \mathrm{~h}$ in the no-fed group was higher than in the fed group $(P<0.05)$ at $0 \mathrm{~h}$ and $3 \mathrm{~h}$. 


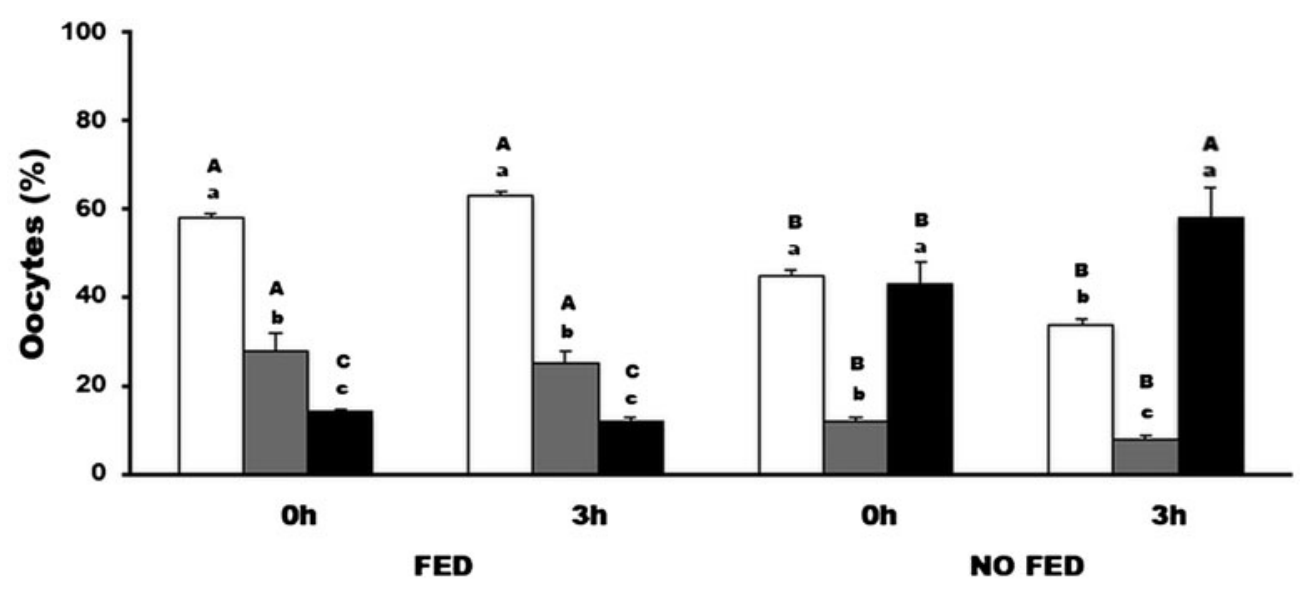

Figure 3 Effects of fed group versus no-fed group on matrinxã oocyte maturation at 0 and $3 \mathrm{~h}$ of culture. Final maturation (open bars), mature (grey bars) and atresic (black bars) stages. Results are represented as means \pm standard error of the mean

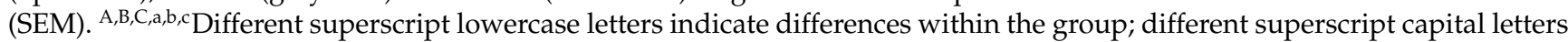
indicate significant differences among the times and the groups. $P<0.05$.

\section{Effects of IGF-1 on oocyte development}

Figure 4 shows the effects of different concentrations of IGF-1 $(0 ; 1 ; 10$ or $50 \mathrm{nM})$ on the percentage of final maturation (Fig. $4 A$ ) mature (Fig. $4 B$ ), and atresic (Fig. 4C) oocytes in both fed and no-fed fish groups at 0 and $3 \mathrm{~h}$ of culture.

\section{Final maturation oocytes}

All concentrations of IGF-1 reduced the percentage of oocytes at the final maturation stage in the fed group at $3 \mathrm{~h}$ of culture compared with the group without IGF-1 $(P<0.05)$. The concentration of $10 \mathrm{nM}$ IGF-1 increased the percentage of final maturation oocytes compared with the other groups $(P<0.05)$ in the no-fed group at $3 \mathrm{~h}$ of culture.

Comparing treatments and times of culture, we observed that in the absence of IGF-1 the percentage of oocytes in final maturation in no-fed group decreased compared with the fed group in both times. Furthermore, there was a lower percentage of oocytes in the final maturation in the no-fed group $(P<0.05)$ cultured at $3 \mathrm{~h}$. The same pattern was observed with IGF-1 $1 \mathrm{nM}$. There was a reduction in the percentage of oocytes in this stage of development for both times in the no-fed group compared with the fed group, and the lowest percentage was observed at $3 \mathrm{~h}$ of culture in the no-fed group $(P<0.05)$. IGF-1 $10 \mathrm{nM}$ increased the percentage of oocytes in final maturation in no-fed fish at $3 \mathrm{~h}$ compared with the other stages at both culture times. Furthermore, the lowest percentage of oocytes in final maturation was observed in the no-fed group at $0 \mathrm{~h}$ of culture $(P<0.05)$. Finally, with IGF-1 $50 \mathrm{nM}$ we observed the reduction in the percentage of mature oocytes at $0 \mathrm{~h}$ and $3 \mathrm{~h}$ of culture in the no-fed group compared with the fed group at the same culture times $(P<0.05)$.

\section{Mature oocytes}

All concentration of IGF-1 increased the percentage of mature oocytes compared with the absence of the peptide in the fed group at $3 \mathrm{~h}$ of culture $(P<0.05)$. At $3 \mathrm{~h}$, in the no-fed group, we observed a significant increase in the percentage of mature oocytes with IGF$11 \mathrm{nM}$ compared with the other concentrations and in the absence of the peptide $(P<0.05)$.

Comparing the fish groups and times of culture, there was a reduction in the percentage of mature oocytes in the no-fed group in the absence of IGF-1 $(P<0.05)$. In the fed and no-fed groups, with IGF-1 1 $\mathrm{nM}$, there was an increase in the percentage of mature oocytes at $3 \mathrm{~h}$ compared with at $0 \mathrm{~h}(P<0.05)$. Besides comparing the same times of culture with $1 \mathrm{nM}$ of the peptide, the percentage of mature oocyte was reduced in the no-fed group compared with the fed group at 0 $\mathrm{h}(P<0.05)$. IGF-1 at $50 \mathrm{nM}$ increased the percentage of mature oocytes at $3 \mathrm{~h}$ compared with $0 \mathrm{~h}$ in the fed group, and reduced the percentage of mature oocytes at both times of culture in the no-fed group compared with the same times in the fed group $(P<0.05)$.

\section{Atresic oocytes}

At $3 \mathrm{~h}$ all IGF-1 concentrations reduced the atresic oocytes percentage compared with IGF-1 $0 \mathrm{nM}$ in the fed group $(P<0.05)$. In relation to the no-fed group at $3 \mathrm{~h}$, all IGF-1 concentrations reduced the percentage of atresic oocytes compare to absence of the peptide $(P<0.05)$. Furthermore, the lowest atresic oocyte percentage was observed with IGF-1 $10 \mathrm{nM}$ in no-fed group at $3 \mathrm{~h}(P<0.05)$. 

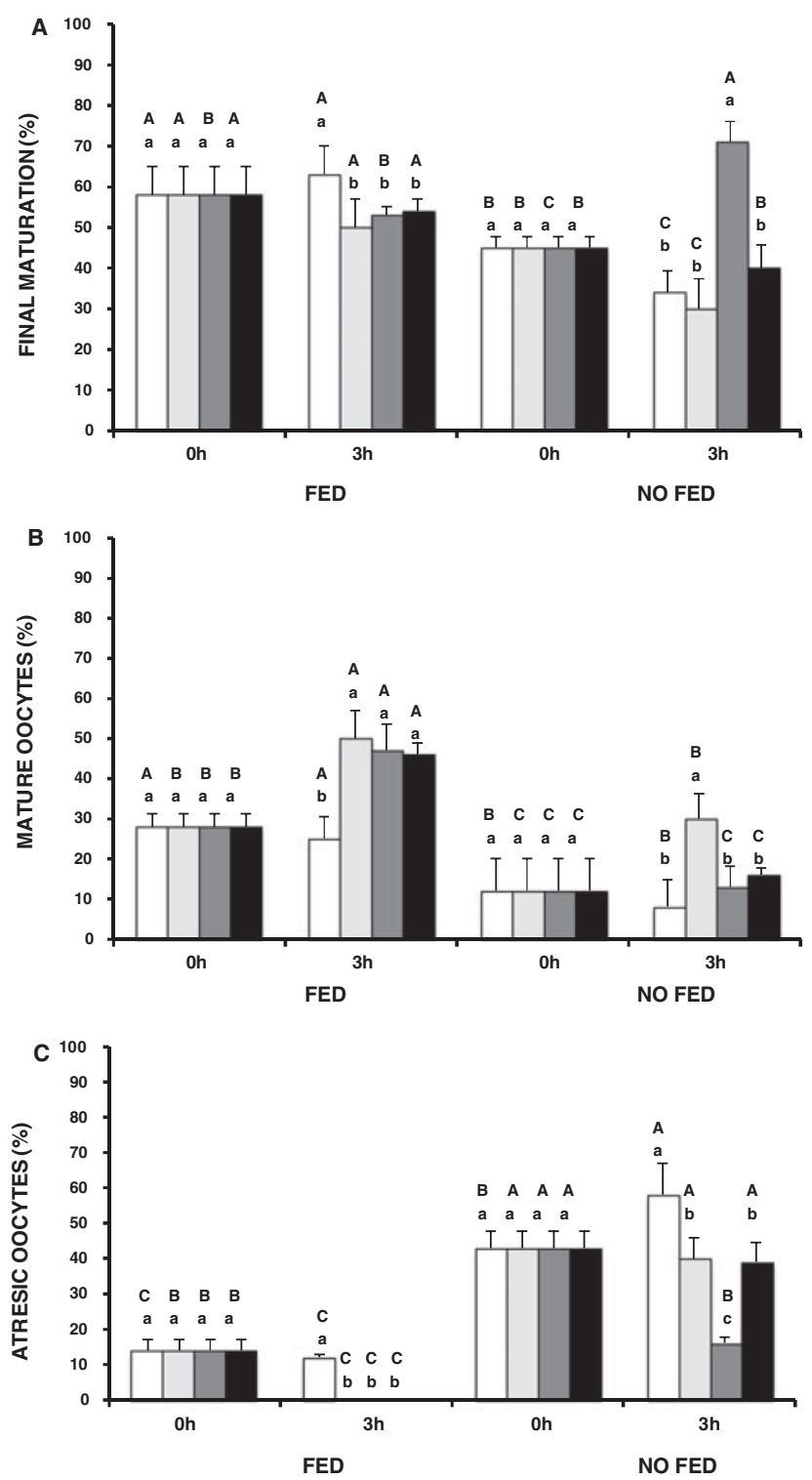

Figure 4 Effects of different concentrations of IGF-1 (0 nM (open bars), $1 \mathrm{nM}$ (light grey bars), $10 \mathrm{nM}$ (dark grey bars) and $50 \mathrm{nM}$ (black bars)) on percentage of matrinxã oocytes in final maturation $(A)$, Mature $(B)$ and Atresic $(C)$ of fed group versus no-fed group at 0 and $3 \mathrm{~h}$ of culture. Results are represented as means \pm standard error of the mean (SEM). $A, B, C, a, b, c$ Different superscript lowercase letters indicate differences within the group; different superscript capital letters indicate significant differences among the times and the groups. $P<0.05$.

Comparing fish groups and times of culture, in the absence of IGF-1, we observed the highest percentage of atresic oocytes in no-fed group at $3 \mathrm{~h}$ compared with the same group at $0 \mathrm{~h}$ and at both times in fed group $(P<0.05)$. All concentrations of IGF-1 reduced to zero the per cent of atresic oocytes in the fed group at 3 $\mathrm{h}$. With IGF-1 at $1 \mathrm{nM}$, there was a higher percentage of atresic oocytes in the no-fed group at 0 and $3 \mathrm{~h}$ compared with the fed group $(P<0.05)$ at both culture times. With IGF-1 $10 \mathrm{nM}$, the percentage of atresic oocytes was higher in the no-fed group at $0 \mathrm{~h}$ of culture compared with the no-fed group at $3 \mathrm{~h}$ and with the fed group at both times $(P<0.05)$. In the presence of IGF$150 \mathrm{nM}$, we observed a higher percentage of atresic oocytes at $0 \mathrm{~h}$ and $3 \mathrm{~h}$ in the no-fed group compared with the fed group at both times $(P<0.05)$.

\section{Discussion}

The results of this study show that there was a reduction in body weight, gonadal somatic index and blood glucose in no-fed animals; as well as an increase in hepatic somatic index and plasma triglycerides levels. The results of in vitro experiments demonstrated the significant effects of culture time and the period of fasting followed by re-feeding on the development stage of the oocytes, as well as the observed IGF-1 effects on the percentage of oocytes at different stages of development: final maturation, mature and atresic. To our knowledge, this study is the first report of results of IGF-1 effects on the development of in vitro matrinxã oocytes. Besides this, the results demonstrate the importance of the feeding management of female breeders of matrinxã during the vitellogenesis period.

The IGF-1 system consists of ligands, cell surface receptors, binding proteins and plays a role in growth, metabolism, osmoregulation, reproduction, behaviour and immunity of teleosts (Reindl \& Sheridan, 2012). The peptide is thought to be a critical mediator of growth hormone $(\mathrm{GH})$ action on teleost growth and it is produced mainly in the liver ( $\mathrm{Xu}$ et al., 2015). The hepatic IGF-1 mRNA expression levels and plasma IGF-1 concentrations have been demonstrated to correlate positively with body growth (Dyer et al., 2004), as well as proliferation and differentiation effects on fish muscle cells (Wuertz et al., 2007b). Our results demonstrate that feeding management applied to the females during vitellogenesis period changes the plasma levels of glucose and triglycerides, decreasing blood glucose and increasing blood triglycerides. Fish were subjected to intermittent cycles of feeding and no feeding. During re-feeding, compensatory biochemical pathways are stimulated in a protective way to recover the energy stores and preserve biological function in fish. As the animals are in feed restriction, glucose consumption increases resulting in reduction of the glycemic. Due to increased use of energy stores, there was a reduction in body weight of females submitted to feed restriction, and as a result of increased hepatic activity related to metabolic changes, there was an increased in hepatic somatic index of females from feed restriction group. In mammals undergoing food 
restriction, there is increased serum $\mathrm{GH}$ and insulin and reduction in plasma IGF -1 (Reindl \& Sheridan, 2012). Plasma modifications of these hormones that control metabolism increase mobilization of calories and reduce body weight. Although we have not examined the effect of dosage of GH or IGF-1, our results demonstrate similar patterns of metabolic adaptations during food restriction.

In fish, as in all vertebrates, IGF-1 is one of the candidate molecules that contributes to body growth and reproduction. IGF-1 exhibits multiple effects on cell growth, differentiation and metabolism (Kagamar et al., 2007). Our results demonstrate a reduction of body weight of females undergoing food restriction during the period of vitellogenesis. These observations are consistent with the bioenergetics theory, which predict that sexually maturating fish should experience reduced somatic growth due to the allocation of energy to gonadal development (Roff, 1983). However, although the ovaries of females submitted to feed restriction presented sizes and weights according to the reproduction period, the GSI was lower than that of the control group females. These data may indicate a specific metabolic adaptation of the species in this study, and even if we have not measured the serum IGF-1 such adaptations may relate possible reductions in serum levels of this peptide. Furthermore, the oocytes cultured in vitro have shown differences in the stages of development between fed daily females and food restriction females. It is noted that food restriction promoted reduction in percentage of final maturation oocytes, and increased the percentage of atresic oocytes. These changes in the stages of oocytes development can be explained by the females need to maintain vital metabolic activities during food restriction period, resulting in changes in reproductive activity, increasing the percentage of atresic oocytes.

The IGFs stimulate acquisition of maturational competence and/or induce oocyte maturation, depending on the species (Kagawa et al., 1994, 1995; Patiño \& Kagawa, 1999; Weber \& Sullivan, 2000, 2005; Weber et al., 2007). Furthermore, theca and especially granulosa follicular cell layer can secrete IGF-1 (Hammond et al., 1985). In some cases, this has been linked to increase of maturation-inducing steroid (MIS) production while, in others, the effects appear to be independent of alterations in steroid output. In addition, the expression of insulin-like growth factor binding protein 1 (IGF-BP1) and IGF-BP6 were upregulated at the time of oocyte maturation in rainbow trout (Kamangar et al., 2006), and IGF-BPs produced by GC, regulate not only the transport of IGFs but also their presentation to cell surface receptors (Hammond et al., 1985; Davoren et al., 1986). Our in vitro experiments show significant effects of IGF-1 on oocytes development from females of matrinxã. After $3 \mathrm{~h}$ of culture of the oocytes from females which were fed daily, all IGF-1 concentrations used decreased the percentage of oocytes on final maturation, increased the percentage of mature oocytes, and reduced to zero the percentage of atresic oocytes. Furthermore, for the oocytes from females submitted to dietary restriction, and cultivated for $3 \mathrm{~h}$, demonstrated that the dose $10 \mathrm{nM}$ IGF-1 increased the percentage of oocytes at the final stage of maturity; at a dose of $1 \mathrm{nM}$ IGF1 there was an increase in the percentage of mature oocytes. These results suggest that constant feeding ensured effects on the percentage of oocytes in final maturation and in mature stages that in the no-fed group was only possible in the presence of peptide, probably because IGF-I can stimulate steroidogenesis, cell division and cell differentiation. Besides this factor, there was a reduction in the percentage of atresic oocytes, particularly when the peptide was used at a dose of $10 \mathrm{nM}$. Thus, our results might suggest that the in vitro actions of IGF-1 stimulate the steroidogenic activities in theca and GC, and may coordinate the synthesis of steroid hormones which control the development of the oocyte, decreasing the percentage of atresic oocytes and stimulate oocyte maturation.

Studies have shown that IGF-1 receptors are present throughout the reproductive cycle, with maximum numbers during primary oocyte growth stage. Furthermore, IGF-1 receptor number decreased in inverse proportion to ovarian follicular maturation, reaching a minimum in the late vitellogenic stage when follicle growth was complete. Thus, regulation of IGF-1 functions throughout the reproductive cycle in ovary seems to depend mainly on the number of receptors present in cellular membrane (Maestro et al., 1997a). Our results of matrinxã oocytes corroborate this data, for a dose of $10 \mathrm{nM}$ IGF-1 there was an increase in the percentage of oocytes in final maturation phase and reduction in the percentage of atresic oocytes. The results suggest that, as there is reduction in the number of IGF-1 receptors during oocyte development, the dose of $10 \mathrm{nM}$ of the peptide was effective in promoting the ultimate maturation of oocytes cultured for $3 \mathrm{~h}$ IGF-1 induced germinal vesicle breakdown (GVBD) - similar to oocyte final maturation - at concentrations as low as $10 \mathrm{nM}$ in striped bass and Fundulus, and $1 \mathrm{nM}$ in red sea bream (Kagawa et al., 1994; Negatu et al., 1998). Furthermore, the use of IGF-1 at $10 \mathrm{nM}$ dose increased the percentage of final maturation oocytes compared with oocytes obtained from females that received a daily ration. Thus, the in vitro action of the peptide at a dose of $10 \mathrm{nM}$ can reverse the reduction in GVBD oocyte number induced by dietary management of females. 
The addition of IGF-1 without FSH stimulated steroidogenesis after $48 \mathrm{~h}$ of chemically defined medium, but the cell proliferation was attained after only $144 \mathrm{~h}$ of culture (Montrezor et al., 2014). The IGF-1 is a potent mitogen and stimulates the mitosis of cultured theca and GC; it increased the synthesis of bovine follicle androgens and E2, and modulates gonadotropin action on those cells (Ginther et al., 2001). The use of IGF-1 in granulosa cell culture of bovine ovarian follicles retained structures and functional characteristics of such cells when challenged with atrial natriuretic peptide (ANP), endothelin-1 (END1) and angiotensin II (Ang II) (Montrezor et al., 2015). Because we did not use FSH in culture, we suggest that the steroidogenic effects on the oocyte cells and oocyte development were dependent on IGF-1 after $3 \mathrm{~h}$ of culture both for oocytes obtained from females with a regular diet as well as for females who underwent food restriction.

In conclusion, the standard of food modification of matrinxã adult females during the reproductive process affects the morphometric characteristics, plasma levels of glucose and triglycerides, and oocyte development. The use of IGF-1 in oocyte culture medium influences the dynamics of oocyte development. Further studies are needed to determine IGF-1 plasma variations over the vitellogenesis period, thus improving studies on the IGF-1 effects on steroidogenesis in vitro.

\section{Acknowledgements}

The authors gratefully acknowledgment Dr Sérgio F. Zaiden for ovarian morphology analysis and Dr Jorge Alberto Achcar for statistical analysis.

\section{Financial support}

This work was support by the Conselho Nacional de Desenvolvimento Científico e Tecnológico (CNPq).

\section{Disclosures}

The authors declare no conflicts of interest, financial or otherwise.

\section{Author contributions}

Author contributions: L.H.M. and E.C.U. conception and design of research; L.H.M. performed experiments; L.H.M. analyzed data; L.H.M. interpreted results of experiments; L.H.M. and E.C.U. prepared figure; L.H.M. and E.C.U. drafted manuscript; L.H.M. and E.C.U. edited and revised manuscript.

\section{References}

Berishivili, G., D'Cotta, H., Baroiller, J.F., Segner, H. \& Reinecke, M. (2006). Differential expression of IGF-I mRNA and peptide in the male and female gonad during early development of bony fish, the tilapia Oreochromis niloticus. Gen. Comp. Endocrinol. 146, 204-10.

Camargo, A.C.S. \& Urbinati, E.C. (2008). Influence of food restriction on the reproduction and larval performance of matrinxã, Brycon cephalus (Spix and Agassiz, 1829). Braz. J. Biol. 68, 869-73.

Celik, O., Aydin, S., Celik, N. \& Yilmaz, M. (2015). Peptides: basic determinants of reproductive functions. Peptides 72, 34-43.

Danforth, E. Jr. \& Burger, A.G. (1989). The impact of nutrition on thyroid hormone physiology and action. Ann. Rev. Nutr. 9, 201-27.

Davoren, J.B., Kasson, B.G., Li, C.H \& Hsueh, A.J.W. (1986). Specific insulin-like growth factor (IGF) I and IIbinding sites on rat granulosa cells: relation to IGF action. Endocrinology 119, 2155-62.

Dyer, A.R., Barlow, C.G., Bransden, M.P., Carter, C.G., Glencross, B.D., Richardson, N. Thomas, P.M., Williams, K.C. \& Carragher, J.F. (2004). Correlation of plasma IGF1 concentrations and growth rat in aquaculture finfish: a tool for assessing the potential of new diets. Aquaculture 236, 583-92.

FAO (2012). The State of World Fisheries and Aquaculture Food and Agriculture Organization of the United Nations, Rome (209 pp).

Ghigo, E., Miola, C., Aimaretti, G., Valente, F., Procopio, M., Arvat, E., Yin-Zhang, W. \& Cammani, F. (1992). Arginine abolishes the inhibitory effect of glucose in the growth hormone response to growth hormone-releasing hormone in man. Metab. Clin. Exp. 41, 1000-3.

Ginther, O.J., Beg, M.A., Bergfelt, D.R., Donadeu, F.X. \& Kot, K. (2001). Follicle selection on monovular species. Biol. Reprod. 65, 638-47.

Hammond, J.M., Lino, J., Baranao, S., Sakaleris, D., Knight, A.B., Romanus, J.A. \& Recher, R.R. (1985). Production of insulin-like growth factors by ovarian granulosa cells. Endocrinology 117, 2553-5.

Kagawa, H., Kobayashi, M., Hasegawa, Y. \& Aida, K. (1994). Insulin and insulin-like growth factor I and II induce final maturation of oocytes of red sea bream, Pargus major, in vitro. Gen. Comp. Endocrinol. 95, 293-300.

Kagawa, H., Moriyama, S. \& Kawauchi, H. (1995). Immunocytochemical localization of IGF-I in the ovary of the red sea bream, Pargus major. Gen. Comp. Endocrinol. 99, 307-15.

Kagawa, H., Gen, K. \& Tanaka, H. (2003). Effects of luteinizing hormone and follicle stimulating-hormone and insulin-like growth factor-I on aromatase activity and P450 aromatase gene expression in the ovarian follicle of red sea bream, Pargus major. Biol. Reprod. 68, 1562-8.

Kagamar, B.B., Rasaee, M.J., Amiri, B.M., Abtahi, B. \& Bahmani, M. (2007). Correlations between circulating insulin-like growth factor-I and thyroxine and cortisol 
hormones levels, and some biometrical traits in female brood stocks during the late stages of sex maturation and in juvenile Persian sturgeon (Acipenser persicus). Fish Physiol. Biochem. 33, 249-57.

Kamangar, B.B., Gabilard, J.C. \& Bobe, J. (2006). Insulinlike growth factor-binding protein (IGFBP)-1, -2, -3, -4, -5, and -6 and IGFBP-related protein 1 during rainbow trout postvitellogenesis and oocyte maturation: molecular characterization, expression profiles, and hormonal regulation. Endocrinology 147, 2399-410.

Lubzen, E., Young, G., Bobe, J. \& Cerdà, J. (2010). Oogenesis in teleosts: how fish eggs are formed. Gen. Comp. Endocrinol. 165, 367-89.

MacKenzie, D.S., Van Putte, C.M. \& Leiner, K.A. (1998). Nutrient regulation of endocrine function in fish. Aquaculture 161, 3-25.

Maestro, M.A., Méndez, E., Párrizas, M. \& Gutiérrez, J. (1997a). Characterization of insulin and insulin-like growth factor-I ovarian receptors during the reproductive cycle of carp (Cyprinus carpio). Biol. Reprod. 56, 1126-32.

Maestro, M.A., Planas, J.V., Moriyama, S., Gutiérrez, J., Planas, J. \& Swanson, P. (1997b). Ovarian receptors for insulin-like growth factor-I (IGF-I) and effects of IGF-I on steroid production by isolated follicle layers of the preovulatory Coho salmon follicle. Gen. Comp. Endocrinol. 106, 189-201.

McIntosh, C.H.S. (1995). Control of gastric acid secretion and the endocrine pancreas by gastrointestinal regulatory peptides. Am. Zool. 35, 455-65.

Miwa, T., Yoshizaki, G., Naka, H., Nakatani, M., Sakai, K., Kobayashi, M. \& Takeuchi, T. (2001). Ovarian steroid synthesis during oocyte maturation and ovulation in Japanese catfish (Silurus asotus). Aquaculture 198, 179-91.

Montrezor, L.H., Piccinato, C.A., Collares, C.V.A., Vireque, A.A. \& Rosa e Silva, A.A.M. (2014). Comparison of medium supplementation on proliferation and hormone production of bovine granulosa cells in a defined culture system. J. Sci. Res. Rep. 3, 645-59.

Montrezor, L.H., Piccinato, C.A., Collares, C.V.A., Vireque, A.A. \& Rosa e Silva, A.A.M. (2015). Effects of angiotensin II, atrial natriuretic peptide and endothelin-1 on proliferation and steroidogenic output of bovine granulosa cells cultured in a chemically defined system. Ann. Reprod. Sci. 152, 8-16.

Nakamura, I., Kusakabe, M. \& Young, G. (2003). Regulation of steroidogenic enzyme mRNAs in rainbow trout (Oncorhynchus mykiss) ovarian follicles in vitro. Fish Physiol. Biochem. 28, 355-6.

Navarro, I. \& Gutiérrez, J. (1995). Fasting and starvation. In Hochachka, P.W. \& Mommsen, T.P. (Eds), Biochemistry and Molecular Biology of Fishes, vol. 4. Elsevier, Amsterdam, pp. 393-434.

Naylor, R.L., Goldburg, R.J., Primavera, J.H., Kautsky, N., Beveridge, M.C.M., Clay, J., Folke, C., Lubchenco, J., Mooney, H. \& Troell, M. (2000). Effect of aquaculture on world fish supplies. Nature 405, 1017-24.

Negatu, Z., Hsiao, S.M. \& Wallace, R.A. (1998). Effects of insulin-like growth factor-I on final oocyte maturation and steroid production in Fundulus heteroclitus. Fish Physiol. Biochem. 19, 13-21.

Pankhurst, N.W. (1997). In vitro steroid production by isolated ovarian follicles of the striped trumpeter. J. Fish Biol. 51, 669-85.

Patiño, R. \& Kagawa, H. (1999). Regulation of gap junctions and oocyte maturational competence by gonadotropin and insulin-like growth factor-I in ovarian follicles of red sea bream. Gen. Comp. Endocrinol. 115, 454-62.

Perrot, V., Moiseeva, E.B., Gozes, Y., Chan, S.J. \& Funkenstein, B. (2000). Insulin-like growth factor receptors and their ligants in gonads of a hermaphroditic species, the gilthead sea bream (Sparus aurata): expression and cellular localization. Biol. Reprod. 63, 229-41.

Reindl, K.M. \& Sheridan, M.A. (2012). Peripheral regulation of the growth hormone-insulin-like growth factor system in fish and other vertebrates. Comp. Biochem. Physiol. 163, 231-45.

Roff, D.A. (1983). An allocation model of growth and reproduction in fish. Can. J. Fish Aquat. Sci. 40, 1395403.

Schmid, A.C., Naef, E., Kloas, W. \& Reinecke, M. (1999). IGF-I and IGF-II in the ovary of a bony fish Oreochromis mossambicus, the tilapia, in situ hybridisation, immunohistochemical localisation, northern blot and cDNA sequence. Mol. Cell. Endocrinol. 156, 141-9.

Urbinati, E.C., Rocha, R.M. \& Carvalho, E.G. (2004). Physiological responses associated with capture and crowding stress in matrinxã Brycon cephalus (Gunther, 1869). Aquacult. Res. 35, 245-9.

Weber, G.M. \& Sullivan, C.V. (2000). Effects of insulin-like growth factor-I on in vitro final oocyte maturation and ovarian steroidogenesis in striped bass, Morone saxatilis. Biol. Reprod. 63, 1049-57.

Weber, G.M. \& Sullivan, C.V. (2005). Insulin-like growth factor-I induces oocyte maturational competence but not meiotic resumption in white bass (Morone chrysops) follicles in vitro: evidence for rapid evolution of insulin-like growth factor action. Biol. Reprod. 72, 1177-86.

Weber, G.M., Moore, A.B. \& Sullivan, C.V. (2007). In vitro actions of insulin-like growth factor-I on ovarian follicle maturation in white perch (Morone americana). Gen. Comp. Endocrinol. 151, 180-7.

Wuertz, S., Gessner, J., Kirschbaum, F. \& Kloas, W. (2007a). Expression of IGF-I and IGF-I receptor in male and female sterlet, Acipenser ruthenus - evidence for an important role in gonad maturation. Comp. Biochem. Physiol. A 147, 22330.

Wuertz, S., Nitsche, A., Jastroch, M., Kesser, J., Klingenspor, M., Kirschbaum, F. \& Kloas, W. (2007b). The reale of IGF-I system for vitellogenesis in maturing female sterlet, Acipenser ruthenium Linnaeus, 1758. Gen. Comp. Endocrinol. 150, 140-50.

Xu, Y., Zang, K., Liu, X., Shi, B., Li, C. \& Shi, X. (2015). Insulinlike growth factors I and II in starry flounder (Platichthys stellatus): molecular cloning and differential expression during embryonic development. Fish Physiol. Biochem. 41, 139-52. 